\title{
Os praiás do sertão: Uma análise filosófica dos espaços imaginários promovidos pelo rito indígena da jurema
}

Sertão's praiás: A philosophical analysis of the imaginary spaces promoted by the indigenous rite of jurema

\author{
ROCHA, Gabriel Kafure da. Doutor/Licenciado e Bacharel em Filosofia \\ Instituto Federal de Educação, Ciência e Tecnologia do Sertão Pernambucano - PE 647, Km 22, PISNC N - 4, \\ Zona Rural, Cx. Postal 277 CEP 56.302-970 Petrolina-PE / Telefone: (87) 2101-8050 / E-mail: \\ gabriel.rocha@ifsertao-pe.edu.br
}

\section{RESUMO:}

O presente artigo faz uma análise da simbologia da Jurema no imaginário indígena nordestino de Pernambuco, de como tal prática se constitui numa retomada de uma unidade política dos índios do sertão. Nesse sentido, o objetivo dessa investigação é entender em que medida a ciência da jurema é uma prática comunitária que constrói um espaço de encontro e quais os elementos do imaginário que constituem esse rito. Para isso, utilizaremos de um referencial teórico ligado aos estudos do imaginário como Gilbert Durand, Gaston Bachelard, assim como estudos antropológicos sobre os Praiás entre os índios do sertão.

\section{Palavras-chave: Máscara; Dança; Encantaria}

\begin{abstract}
:
This paper intends to analyze Juremas symbology in the Northeastern indigenous imaginary of Pernambuco, as this practice constitutes a resumption of a political unity of the Indians of the Sertão. In this sense, the objective of this investigation is to understand to what extent the science of jurema is a community practice that builds a space of encounter and which elements of the imaginary that constitute this rite. For this, we will use a theoretical reference linked to the studies of the imaginary like Gilbert Durand, Gaston Bachelard, as well as anthropological studies on the Praiás among the Indians of the sertão.
\end{abstract}

Keywords: Mask; Dance; Enchantery;

\section{Introdução}

Sabemos que desde os primeiros povos a habitar as américas a jurema era considerada uma planta sagrada, um fato que marca isso é, por exemplo, o fato das pinturas rupestres em São Raimundo Nonato - PI, retratarem diversos desenhos onde uma árvore espinhosa figura retratando os rituais e atividades cotidianas na época. Pelo fato de não haver informações mais precisas e completas da historicidade da difusão do uso da Jurema. Então, as formulações neste caso sobre as origens dessa prática são especulações. A hipótese mais recorrente nos reagrupamentos étnicos surge devido a extinção das políticas dos aldeamentos, assim esse rearranjo surge de diversos grupos diferentes que migravam de vários lugares, tanto da costa quanto dos interiores do Estado.

0 termo jurema que se utiliza como senso geral e genérico vem do tupi yu-r-ema - planta espinhosa. Justamente, devido ao encontro de colonizadores com os indígenas na costa e isso se firmou genericamente com o processo civilizatório, no entanto, as denominações e o corpus simbólico da planta ainda hoje assumem compreensões singulares nos grupos sociais.

Do ponto de vista acadêmico, os estudos antropológicos da Jurema apenas se tornam 
ROCHA, G. K. (2020)

Os praiás do sertão: Uma análise filosófica dos espaços imaginários promovidos pelo rito indígena da jurema

sistemáticos e com um viés mais investigativo e etnográfico somente em 1920 em diante, uma das marcas dessa investigação está relacionada à expedição de Mário de Andrade ao nordeste, onde, em uma filmagem curta se retrata o culto da jurema no litoral da Paraíba.

O rito da jurema, em suas diversas nuances, tem representação importante na matriz indígena das etnias do sertão do nordeste. Nessa linha, os praiás é a nomenclatura que denomina o nome de um ritual mais ligado às etnias Kambiwá (Ibimirim - PE), Pankararu (Tacaratu-PE). Ou seja, as etnias do sertão que vivem entre as divisas de Pernambuco, Alagoas e Bahia. Outras etnias de estados vizinhos como Kantaruré/BA, Kalancó/AL, Geripankó/AL, Pankararé/BA, Catokin/AL, Karuazu/AL, Koiupancá/AL também se utilizam dessa cultura tanto da jurema como dos praiás, entidades que dançam durante o ritual da jurema. Contudo, em outras etnias, o ritual da jurema assume nomes como toré e ouricuri. Decidimos então abordar essa nomenclatura pela proximidade regional e com o mistério que a jurema e os praiás evocam no imaginário humano.

Praiás é como se chama a vestimenta de fibra de caroá que cobre da cabeças aos pés os encantados que levam em suas mãos um maracá e geralmente uma gaita. Os praiás são entidades que habitam a natureza, eles são intermediários entre a terra e o céu, atuando terapeuticamente no plano da dádiva e contra-dádiva da relação com a pessoa e a realidade, principalmente na recuperação de doenças e cura. Tais conceitos herdados da teoria de Marcel Mauss, identificam aqui o ato da generosidade e solidariedade que essa herança do imaginário provoca, a contra-dádiva é o redobramento da dádiva a partir de uma dialética social do prestígio e da honra que tais rituais geram na comunidade. Assim, revelando-nos a importância da história contada pelos próprios indígenas na formação de um pluriverso, ou seja, cosmologias distintas que se tensionam com as lógicas hegemônicas do estado brasileiro.

Na década de 1940, em descrição sobre o ritual do ajucá, o pesquisador Oswaldo Lima fala da importância do ritual de preparação da jurema, da circularidade das pessoas e da defumação com o cachimbo sob o chá, fazendo uma fumaça em forma de cruz, além do cachimbo com a jurema passar de mão em mão e o início do ritual de entoação de cânticos para nossa senhora, aos encantados, Jesus e até mesmo ao Padre Cícero.

A utilização da Jurema e das cascas das árvores acima mencionadas, parece ter sido prática geral entre as populações do sertão do Nordeste, Cariri e Gê, pois conseguimos obter de índios Chucurú" da Serra de Orobá, idênticas informações sobre preparação das bebidas (LIMA, 1946, p. 54).

Provavelmente junto com o mel de abelha, Urucú ou Mandassaia, que acaba por fermentar a bebida adquirindo um caráter alcoólico. Lima descreve essa relação com a jurema como uma fitolatria dos índios do nordeste, mas que há relatos do uso até mesmo entre índios no Pará. O que encontra correspondência atualmente com a força do sincretismo entre a umbanda e a encantaria maranhense no Pará. Contudo, Lima diz que os pesquisadores da época poderiam ter confundido a jurema com a beberragem feita com o cipó, Banisteria Caapi, conhecido na região do Pará como Cabí. O que Lima considera fato incontestável é que os Tupi eram indígenas nômades que provavelmente estavam procurando novas terras tanto ao norte quanto na região dos andes. 
ROCHA, G. K. (2020)

Os praiás do sertão: Uma análise filosófica dos espaços imaginários promovidos pelo rito indígena da jurema

A difusão de um elemento dionisíaco de cultura como a Jurema teria de ser muito ampla, ultrapassando mesmo os limites geográficos da espécie botânica, porque o caboclo juremeiro não esqueceria jamais os transportes deliciosos que uma vez experimentou. E em suas noites melancólicas, ao redor da fogueira, ele havia de contar aos seus novos irmãos das terras-semJurema, o que era a Jurema, - uma árvore sagrada capaz de fazer ver "muita coisa bonita mandada por Deus" (LIMA, 1946, p. 67)

De todo modo, os ditos "Caboclos juremeiros" sofreram grande perseguição policial devido aos resquícios catequistas da colonização, muitos desses índios então costumavam negar o uso da jurema.

\section{O imaginário praiá da jurema}

Um praiá surge no imaginário ao escolher uma pessoa para zelar e cuidar deles. Geralmente eles começam aparecendo em um sonho e informando as suas intenções, para logo depois passar a se manifestar no espaço particular de uma pessoa ou família, revelando seu nome e seu cântico ou toante.

Após tal apresentação e familiarização, o encantado passa a ser cultuado no terreiro da aldeia nas festas, ganhando a vestimenta e a máscara. Contudo, o homem que vai vestir o praiá fica em sigilo, ou seja, somente o zelador sambe quem está por trás da máscara. Para Bachelard, as máscaras são sonhos fixados e os sonhos máscaras em movimento. Logo, a dança é o sonho e a morte é a máscara absoluta

A máscara realiza, em suma, o direito que nos concedemos de nos desdobrar. Oferece uma avenida de ser a nosso duplo, a um duplo potencial ao qual não soubemos conferir o direito de existir, mas que é a própria sombra de nosso ser, sombra projetada não atrás mas adiante de nosso ser (BACHELARD, 1986, p. 173).

É sobre essa sombra do ser de cada um que se dá o dilema dos praiás, de surgirem e serem aceitos. Ou seja, ser estabelecido na comunidade, o praiá deve ser alimentado a partir da fumaça dos cachimbos, geralmente seu zelador, que por sua vez se priva durante tais épocas de relações sexuais e bebida. Já o dançador só realiza esse jejum e privações um dia antes de vestir o praiá.

Essa geração de novos praiás, em algumas tribos indígenas geralmente é colocada em suspeita, devido a uma postura ortodoxa dos mais idosos. Levantar um praiá tem um significado simbólico de adentrar nos espaços coletivos ritualísticos, levando a uma dimensão do poder político das famílias, e o praiá representa muito o poder da dança, já que os rituais são realizados para essa movimentação.

Durante a "dança" dos praiás um cantador executa cânticos cerimoniais diferentes dos que são executados durante o toré. Na "dança" dos praiás são executados cânticos chamados de toantes. Os toantes são cânticos feitos numa espécie de língua ancestral (ALBUQUERQUE, 2010, p. 18).

No seu aspecto mais essencial, os praiás representam a expressão de seres míticos do imaginário religioso que habitam nos arredores de suas aldeias. São também considerados como mestre-guias na mata branca, guiando aos pajés com sabedoria para encontrar a ciência indígena do vinho da jurema.

Onde o papel sacramental do consumo dos "vinhos" não só para os semitas, 
ROCHA, G. K. (2020)

Os praiás do sertão: Uma análise filosófica dos espaços imaginários promovidos pelo rito indígena da jurema

cristãos e sobretudo mundanos, como também para os indígenas da América do Sul [...] A virtude destas beberagens é ao mesmo tempo criar uma ligação mística entre os participantes e transformar a condição triste do homem. (DURAND, 2012, p. 261).

A jurema é um termo polissêmico para designar um arbusto cientificamente chamado de mimosa hostilis, da subespécie da jurema preta, que guarda um valor medicinal, que se delineia pela transição do arbusto, de bebida e de uma região espiritual.

Mais que isso, quando invocados pelo canto de seus "toantes" ou "linhas" compartilhados, com variações, por todas essas etnias, os principais "encantados" como que circulam pelas várias aldeias, cada uma delas uma "ponta de rama", tal como ancestrais míticos que vêm validar no plano simbólico do sagrado a articulação política que tem prevalecido entre os vários povos indígenas do Nordeste em sua lenta e atribulada caminhada conjunta rumo ao reconhecimento oficial e à retomada da terra. Ao dramatizar na dança coletiva o imaginário do passado mítico presente na poesia cantada dos toantes, gente simples e analfabeta encontrou uma linguagem de poucos conceitos, mas de imagens eloquentes com que falar de si para si (TROMBONI, 2012, p. 114).

Desse modo, nos interessa aqui falar justamente como essa prática ritualística do aspecto simbólico-imaginário parece criar linhas poéticas da subjetividade, ou seja, como ser ou se tornar indígena diante do desenvolvimento do imaginário juremeiro.

"Bachelard parece dominar melhor o problema ao aperceber-se imediatamente de que a assimilação subjetiva desempenha um papel importante no encadeamento dos símbolos e suas motivações” (DURAND, 2012, p. 34). Assim, Praiás são personificações de espíritos encantados que dançam simbolicamente em terreiros ao som de toantes. No sentido temporal, o ritual é iniciado quando se encontra o primeiro imbu maduro da safra, geralmente ocorre no mês de dezembro, a festa tem início pela manhã com brincadeiras de praiás. Dado início a festa, os cantadores puxam os toantes, enquanto os praiás dançam fazendo um grande círculo numa fila indiana no terreiro. Dançam sozinhos ou em par, nessa duplicidade "A máscara e a dança são representações figurativas, [...]. Enfim, máscaras e danças integram-se em puras representações " (DURAND, 2012, p. 406).

Essa parte do ritual tem um intervalo somente na hora do almoço, quando é servido a comida dos praiás. 0 “'dono do terreiro', encantado que abre o terreiro, é o primeiro a ser servido, seguido pelos cantadores, pelos praiás, e por último, a comunidade expectadora" (BARRETTO, 2010, p. 118). Este ritual tem como objetivo prever como dará a safra do ano seguinte se o grupo vencedor for do lado oeste isso significa que a safra será boa, caso contrário não haverá muita chuva o que implica dizer que terão uma má colheita no ano seguinte.

A Corrida do Imbu, entre os Pankararu, aponta as relações existentes entre homens, encantados e obrigações, onde as penitências se forem desrespeitadas geram desordens sociais. Durante o ritual tem a queima do cansanção, em que os índios dançam levando em suas costas plantas urticárias que simboliza o pagamento de penitência e petições de proteção aos encantados, aquele índio que dançar mais tempo com a planta urticária em suas costas, este terá atendido mais rápido seus pedidos.

Analisando todo esse contexto ritualístico mágico-sagrado, compreendemos que tais práticas 
ROCHA, G. K. (2020)

Os praiás do sertão: Uma análise filosófica dos espaços imaginários promovidos pelo rito indígena da jurema

são fontes norteadoras para o reconhecimento étnico, a Corrida do Imbu, por sua vez foi um mecanismo utilizado para o reconhecimento étnico.

Assim, os indígenas vão para as Caatingas, sentir os espíritos das matas, ouvir seus conselhos, ver a resposta dos ventos, o movimento das árvores, e coletam a raiz da Jurema, realizando mais um Ritual. Segundo Kurt Nimuendaju e os Kamaruru-Kariri

\begin{abstract}
A jurema mostra o mundo inteiro a quem a bebe: vê-se o céu aberto, cujo fundo é inteiramente vermelho; vê-se a". Morada luminosa de Deus; vê-se o campo de flores onde habitam as almas dos índios mortos, separadas das almas dos outros. Ao fundo vê-se uma serra azul. Veem-se as aves do campo de flores: beija-flores, sofrês e sabiás. À sua entrada estão os rochedos que se entrechocam, esmagando as almas dos maus quando estas querem passar entre eles. Vê-se como o sol passa por debaixo da terra. Vê-se também a ave do trovão, que é desta altura (um metro). Seus olhos são como os da arara, suas pernas são vermelhas e no alto da sua cabeça ela traz um enorme penacho. Abrindo e fechando este penacho, ela produz o raio e, quando corre para lá e para cá, o trovão (NIMUENDAJU, 1986, p. 53).
\end{abstract}

O ponto de curiosidade que temos presente no caso indígena é justamente como essas etnias reformularam ou não esses usos e como mantêm suas particularidades associadas às micropolíticas da tradição e do pertencimento étnico. Os Tuxá, Fulni-ô e Pankararu são considerados difusores por antropólogos, mas, cada etnia atribui um nome autoral para a planta, por exemplo: para os Fulni-ô é kotcha, para Xucuru é Veuka. Diferenciar o culto de outros como os Kalankó é um dado interessante já que tratamos de troncos antigos e pontas de rama, isso deixa um repertório de perspectivas em aberto para levantar propostas futuras de estudo.

Como Arruti (2008) coloca, o "ressurgimento das sementes" parte do dever de cada grupo de reaprender a gerar sua semente, ou seja, aprender com outra etnia, mas particularizar seu uso, é meio o que ocorre com o ato de fazer a sua pisada no toré, pegar um toré genérico e torná-lo particular, esse é um dos sentidos da ressignificação identitária do culto da jurema entre as etnias indígenas no sertão do nordeste, e o valor do imaginário desse rito é fundamental para a sobrevivência na medida em que a jurema é ela também uma planta que sobrevive no sertão apesar de toda seca.

Nesse sentido, deixamos por fim uma reflexão sobre esse mundo mostrado pela jurema indígena acerca das relações aqui apresentadas na imagem dos praiás: essa roupa que dança, imagem do encantado, espíritos da floresta que tem uma semelhança muito grande com o arquétipo do omolu no candomblé ou mesmo dos eguns dos cultos do candomblé na ilha de Itaparica. Desse modo, seguese duas hipóteses finais: uma delas é que os índios foragidos do litoral para o sertão se identificaram com a cultura africana e a incorporaram aos seus ritos; a segunda delas é a contrária, a de que os negros se identificaram também com os indígenas ao encarar a forma do encantado da natureza como um mesmo desenho que ironicamente é também utilizado em algumas regiões da própria África.

\title{
Considerações Finais
}

Durante muito tempo, as análises sobre a jurema se desdobraram na ideia do complexo no 
ROCHA, G. K. (2020)

Os praiás do sertão: Uma análise filosófica dos espaços imaginários promovidos pelo rito indígena da jurema

caso indígena, Tromboni foi um dos que foram além para retratar esse difusionismo caracterizado como "complexo ritual da jurema", abordando essa mistura afro-indígena e um complexo ritual na relação planta/símbolo, evidentemente isso apresenta muitas problemáticas de delimitação do ponto de vista antropológico, principalmente, porque determinados indígenas no Nordeste não se identificam com essa mistura em suas linhagens étnicas. Contudo, do ponto de vista do imaginário, é a relação entre filosofia e ciências da religião que pode dar conta de alguns tópicos para problematização que estão mais vinculados em torno de conceitos imaginários e religiosos do que de etnicidade em si.

Os rituais indígenas compõem sistemas etnoecológicos, na interação entre o ser indígena e os sistemas bióticos e abióticos da Caatinga. 0 que os leva a reunir conhecimentos tradicionais que são transmitidos entre gerações, como o conhecimento meteorológico, pedológico, botânico, etnobotânico, em síntese, etnoecológico. Isto ocorre, devido ao comensalismo presente entre o universo Botânico, Encantados e Indígenas.

Os Pankararé não percebem a Jurema Preta simplesmente como uma planta, na forma como concebida na Botânica. Para esse povo, essa planta é um elemento religioso, é considerada uma das etnoespécies da Caatinga mais importantes para os seus Rituais Sagrados, uma vez que também é cultuada como um dos Encantados e a quem são atribuídos à força de uma das entidades mais fortes nas Tradições Indígenas Pankararé: o espírito de um índio, um caboclo encantado. E por fazer parte desta natureza, criaram formas de manejo sustentável, respeitam e preservam o ecossistema em que vivem.

\section{Referências Bibliográficas}

ALBUQUERQUE, Marcos. A intenção pankararu (a "dança dos praiás" como tradução intercultural na cidade de São Paulo). Cadernos do LEME, Campina Grande, vol. 2, nº 1, p. 2 - 33. jan./ jun. 2010.

ARRUTI, José Maurício. "Quilombos". In: SANSONE, Livio e PINHO, Osmundo. Raça: novas perspectivas antropológicas. 2 ed. Salvador: Associação Brasileira de Antropologia; EDUFBA, 2008, pp. 315-350.

BACHELARD, Gaston. O direito de sonhar. Trad. José Américo Pessanha. São Paulo: Difel, 1986.

BARRETTO, Juliana. Corridas do Imbu: Rituais e imagens entre os índios Karuazu. Dissertação de mestrado do PPG de Antropologia da UFPE. Recife, 2010.

DURAND, Gilbert. As estruturas antropológicas do imaginário. Trad. Helder Godinho. São Paulo: Martins Fontes, 2012.

LIMA, Oswaldo. Observações sobre o "vinho da Jurema" utilizado pelos Índios Pancarú de Tacaratú (Pernambuco) Arquivos do Instituto de Pesquisas Agronómicas, vol. 4, pp. 45-80, 1946.

NIMUENDAJU, Curt. Mitos indígenas inéditos na obra de Curt Nimuendaju. In: Revista do Patrimônio Histórico e Artístico Nacional, ${ }^{\circ}$ 21, 1986.

TROMBONI, Marcos. Parte I - Índios e caboclos na formação da nação brasileira: A Jurema das ramas até o tronco: ensaio sobre algumas categorias de classificação religiosa. In: CARVALHO, MR., and CARVALHO, AM., org. Índios e caboclos: a história recontada [online]. Salvador: EDUFBA, 2012, pp. 95-125. 